\title{
Ethnogrinding Database: A tool to collect and connect worldwide information on ethnological and ethnoarchaeological hand-milling systems
}

\author{
Natàlia Alonso ${ }^{1}$, Georgina Prats ${ }^{2}$, Themis Roustanis ${ }^{2}$, Panos Tokmakides ${ }^{2}$, \\ Soultana Maria Valamoti ${ }^{3}$ \\ 1. GIP-3DPatrimoni, Dept. d'Història, INDEST, Universitat de Lleida, Pl. Victor Siurana, 1, 25003 Lleida, \\ Catalonia, Spain. Email: nalonso@historia.udl.cat \\ 2. School of History and Archaeology, Aristotle University of Thessaloniki, 54124 Thessaloniki, Greece. \\ Email: Prats: geoprats@gmail.com; Roustanis: roustanis@gmail.com; Tokmakides: ptokmaki@gmail.com \\ 3. LIRA Laboratory, Department of Archaeology, School of History and Archaeology, Aristotle University of \\ Thessaloniki, 54124 Thessaloniki \& Center for Interdisciplinary Research and Innovation (CIRI-AUTH), \\ Balkan Center, Buildings A\&B, Thessaloniki, 10th km, Thessaloniki-Thermi Rd, P.O. Box 8318, 57001, \\ Thessaloniki, Greece. Email: sval@hist.auth.gr
}

\begin{abstract}
:
This study advances research carried out during the creation of a bibliographic database of ethnological information regarding hand milling systems in the framework of the ERC-Project PLANTCULT Identifying the Food Cultures of Ancient Europe: an interdisciplinary investigation of plant ingredients, culinary transformation and evolution through time led by S.M. Valamoti. The main aims of the database are to collect information linked to the processes of plant grinding with handmills, basically driven with a back and forth motion, in different parts of the world and to connect this information to specific archaeological, textual and experimental data, in particular that associated with food preparation. The database is structured in various sections (basically publications, plants and other foodstuffs, milling processes, products, querns and use and social context), in order to facilitate systematic extraction of all relevant information from a wide range of publications that discuss or report on grinding tools in regions and societies of the recent past. The base records a wide range of activities ranging from tool manufacture to end products that include procurement of raw materials, the preparation sequence of tools (including tool-kits), spatial associations, gender issues, plant ingredients and end products. All aspects recorded in the database are interconnected as are the numerous economic and social relationships of the milling process.
\end{abstract}

Keywords: ethnoarchaeology; ethnology; handmills; plants; food; PLANTCULT project

\section{Introduction and background}

The culinary transformation of plant ingredients into food is closely linked to the shaping of social and cultural identity in Prehistory and remains little explored and comprehended. The ERC project PLANTCULT - Identifying the food cultures of ancient Europe: an

Published by the School of History, Classics and Archaeology, University of Edinburgh ISSN: 2055-0472. URL: http://journals.ed.ac.uk/lithicstudies/ 
interdisciplinary investigation of plant ingredients, culinary transformation and evolution through time (ERC-Consolidator Project, 2016-2021 ERC- 2015-CoG) aims to offer a new understanding of this process by applying a methodology that integrates ancient plant food remains and their associated equipment. The project aims to develop a methodology for deciphering culinary transformation of plants from the Aegean to Central Europe spanning the Neolithic to the Iron Age (7th - 1st millennium BCE), by means of an interdisciplinary, contextualised approach to plant ingredients, food remains, processing and cooking techniques and related equipment. The project also includes analyses of plant food macro- and micro-remains, experimentation and ethnographic observations (Valamoti et al. 2017; 2020).

The Ethnogrinding database is a bibliographic database developed in the framework of the project. Its two main objectives are to carry out a comprehensive compilation of published information on the processes of manual plant milling in different parts of the world and then relate or connect archaeological finds, ancient written sources, and experimental data linked to plant milling (in particular that associated with food preparation) with the ethnographic record. This is a work in progress and the aim of the current article is hence to offer an overview of the design and function of the interface that will ultimately be accessible to the scientific community interested in the use and characteristics of hand-driven mills.

Furthermore, the Ethnogrinding database will include a listing of plant products and related equipment as the interface, the subject of this paper, will be accessible on-line to a wide public in a simple on-line form preceding the conclusion of the PLANT CULT project in 2021.

\section{The Ethnoarchaeology of vegetal grinding: the background of the Ethnographic database}

The grinding or pounding of a number of organic and inorganic materials, countless types of vegetables, and especially cereals, are tasks closely associated to the daily life of human societies throughout time. The best-known archaeological artefacts of this process are the mills themselves, although they in fact only form part of a more complex sequence of operations involving other implements such as mortars or sieves. Furthermore, processing foodstuffs also results in a much wider range of products than is commonly considered. In fact, the grinding or pounding tool is but a single link in a much more complex process involving multiple operations.

The database presented here, for the moment, focuses on querns driven with a back and forth motion, while rotary querns will be added later. These two mills are the only types employed during prehistoric and protohistoric times. An earlier ethnoarchaeological and bibliographic approach to grinding, mills and multiple related aspects undertaken by one of the authors of this paper yielded a first perspective of this variability (Alonso 2019). This prior research has served as the base to establish the multitude of parameters related to milling and the starting point to structure the complex database described in this article.

Many of the data offered by these publications are of immense interest. There is, for example, the question of the relationship between mill dimension or morphology and rock type, functionality, and socioeconomic aspects, topics that are explored in more complete case studies. Preliminary analyses, however, indicate that the associations between these variables are not clear. The relationship between the functional needs and the morphology of back and forth querns, for example, do not appear to be direct or consistent, and, on the other hand, morphological variations do not necessarily imply functional variations. An early approach, in fact, reveals that identical millstone typology does not imply identical function (or vice versa) as throughout their long life (on an average several decades) millstone morphology can undergo gradual transformations (Alonso 2019). 
Another noteworthy aspect is that in certain cases two categories of back and forth querns serve respectively to grind cereals and condiments while in other conditions the same quern can be multifunctional (with the exception of certain materials such as oleaginous seeds). Moreover, aspects such as the choice of rock for each of the two stones, grinding surface dressing frequency and other factors can affect a millstone's life. These are essential aspects to take into consideration when studying materials unearthed during archaeological excavations.

Furthermore, beyond the question of the millstones themselves, it must be taken into account that mills intervene in various types of processing such that of groats, semolina, flours of cereals and other plants, beverages and beers, sauces and condiments, and medications. The list of fruits, seeds, leaves, roots or tubers subject to grinding or pounding to render them apt for consumption is infinite not only in societies of traditional technology, but throughout the cuisines of the world. Unfortunately, information about food processing is disparate depending on the species and artefacts. Most of the ethnographic and ethnoarchaeological studies on mills, for example, focus on back and forth querns (with some exceptions such as Parton 2011 and Alonso et al. 2014 on rotary querns, or Ertug-Yaras 2002 and Baudais \& Lundstrom-Baudais 2002 centring on a variety of mill types), whereas the data on processed cereals derives from studies of corn, sorghum, millet and finger millet. There are practically no parallels focusing on the milling of wheats or barleys (except for dehusking tasks) in spite of the fact that these cereals are the most common in the Prehistory and Protohistory of Europe and the Mediterranean, areas where they were most likely processed with back and forth querns (as observed by Samuel 2010: 457).

In fact, ethnoarchaeological analyses of the processes of grinding cereals rarely display any interest in detailing each of their stages or the different products they yield (Alonso et al. 2014, Antolín et al. 2016). A series of steps is in fact required to grind cereals. And they vary depending on the type of cereal (hulled or naked), the degree of cleanliness during storage, and the desired or final product(s). These are operational sequences aimed at obtaining products that can serve both for immediate cooking and medium term conservation (e.g., for an overview on bulgur and trachanas see Valamoti 2011).

Therefore, there are multiple interconnected aspects that must be taken into account when carrying out more in-depth, wider information-based research that can facilitate access to a very broad set of data allowing the interconnection of evidence gleaned from archaeological and written records. The integrative approach of the PLANTCULT project therefore offers a great opportunity to carry out such a complex task as it adopts the ambitious goal of offering insight into milling and its culinary, spatial, socioeconomic and cultural parameters.

\section{The structure of the ethnographic database}

The studies cited above, especially the research of Alonso (2019), served as guides to establish a structure and advance a system to organise the information. Multiple aspects as to grinding are gleaned from specialised publications hence the label Publications serves as interface's main tab. This tab comprises books, articles, photographs, etc., that serve as the backbone to all the other tabs. A series of descriptive tabs are completed for the information from each publication - on the condition that the information is complete. The tabs begin with data referring to the grinding or pounding of raw materials (mainly plants and other foodstuffs or other types of materials), the different stages of the grinding process and the resulting products (Figure 1). Other tabs refer to the grinding mechanisms, mainly hand driven back and forth and rotary querns, their respective use and social context, as well as other tools that take part in the process (mortars, grinding surface pecking tools and sieves). The database 
concludes with tabs leading to millstone quarries and millstone manufacture. All of these differing aspects are linked with the objective to gain insight into their many connections and relationships.

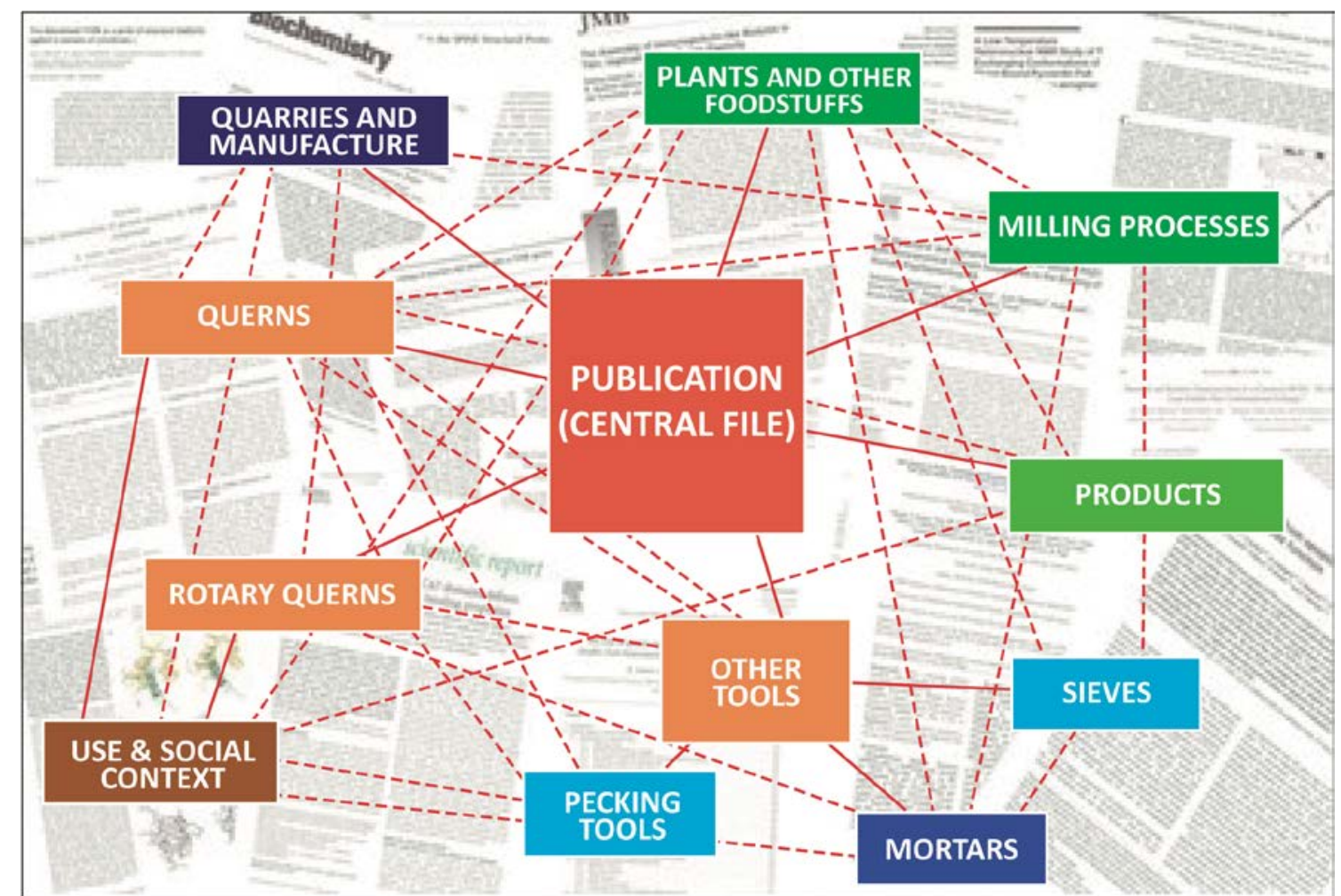

Figure 1. Aspects on grinding systems gleaned from specialised publications that serve as the basis for data collection.

\subsection{Computer context}

The system that supports the data collected by the researchers was developed from the ground up along the lines of a client-server architecture with the intention to develop a collaboration of researchers participating in the PLANTCULT project from a variety of European cities.

The system was developed with a n-tier architecture and consists of three Virtual Machines. The first is for the database layer, the second for the application layer and the third for the presentation layer. The three servers that host the PLANTCULT system are an MSSQL server used for the databases, an ArcGIS server for the spatial information and an application server to run the frontend of the interfaces (ASP.NET applications) and host the web services. The structure of the data was aligned with the CIDOC CRM and Core Data Standard for Archaeological Sites and Monuments. Several databases were designed and implemented as operational data sources to be fused in a later stage in a Data Warehouse System. The information was collected using a multi-dimensional structure and through the Data Warehouse to support complex domain-specific or field-oriented analysis processes.

The ethnographic database of the grinding tools is one of the Operational Databases which will be linked with its appropriate translation tools. The final goal is to achieve complicated queries on the Data Warehouse and GIS system which will offer researchers a tool to investigate cross-disciplinary correlations and spatiotemporal relationships. The initial data sources possess a unified model to manage spatial and temporal information. This approach offers researchers with the option to extract information specific to their field in combination with other subjects. 
The ethnographic grinding tools database presents a rather complex structure whose schema is depicted in Figure 2. Additionally, the schema comprises 73 look-up-tables (LUT) that are omitted from the Figure.

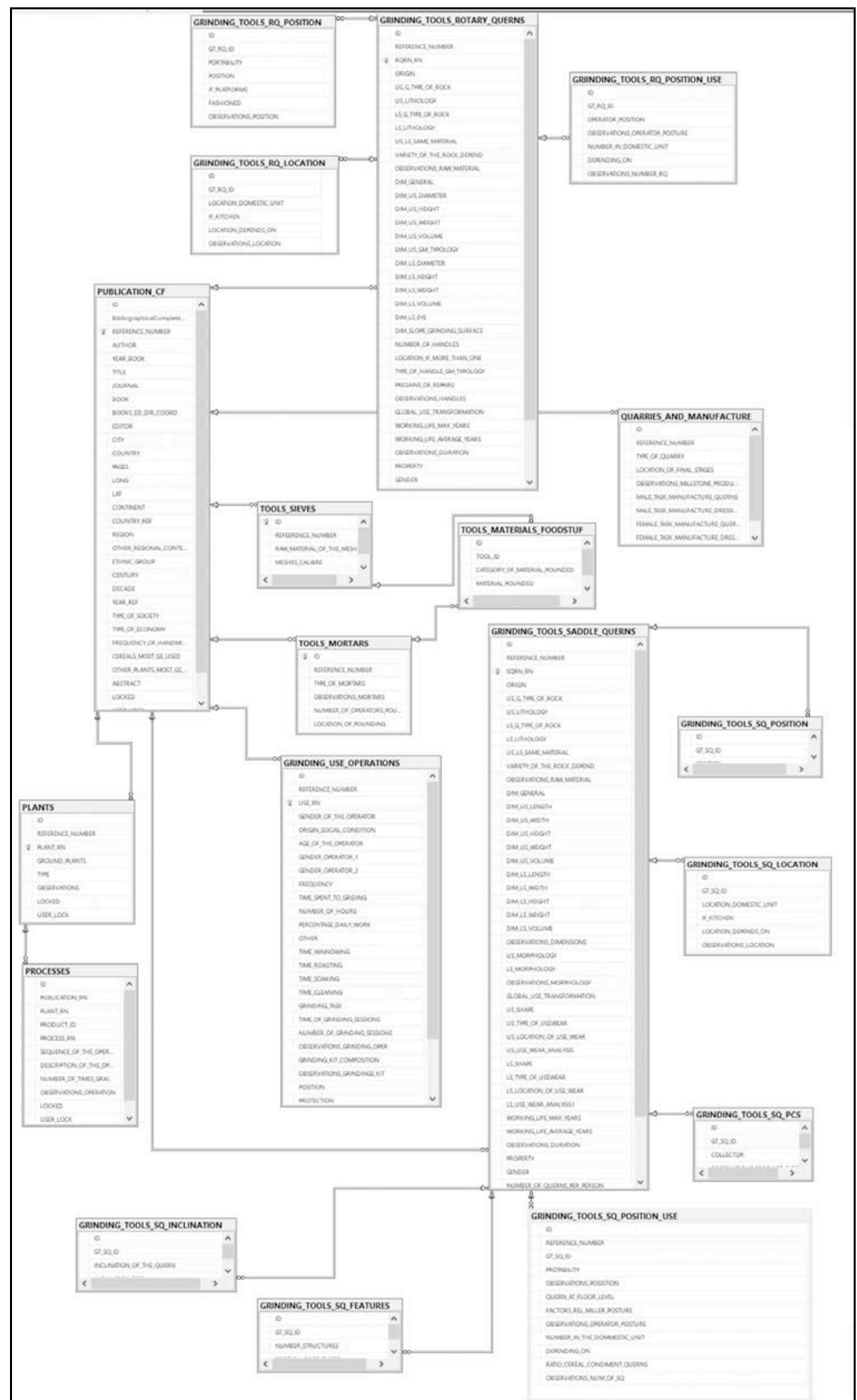

Figure 2. Schema of the computer structure of the Ethnogrinding database. 


\subsection{Structure and contents}

Many aspects were taken into consideration when developing this database design based on background research conducted by the first author (Alonso 2019). Below are the details of the notions regarding each of the tabs of the interface. Yet it must not be forgotten that they are all interrelated.

\subsubsection{Publications (Figure 3)}

The organisation of the database, as mentioned above, is founded on the central Publications tab that serves to structure all the other tabs. This tab contains the habitual information about the book or working document: author(s), year, title, magazine, publisher, city, country, pages, ISBN-ISSN and DOI (if it exists). All registered publications are accompanied by their reference number (PBL_RN). It must be noted that each milling process described in a publication making use of a particular type of tool receives an individual registration number, whether it be a quern or mortar that yields a specific product (bread, couscous, flatbreads, etc).

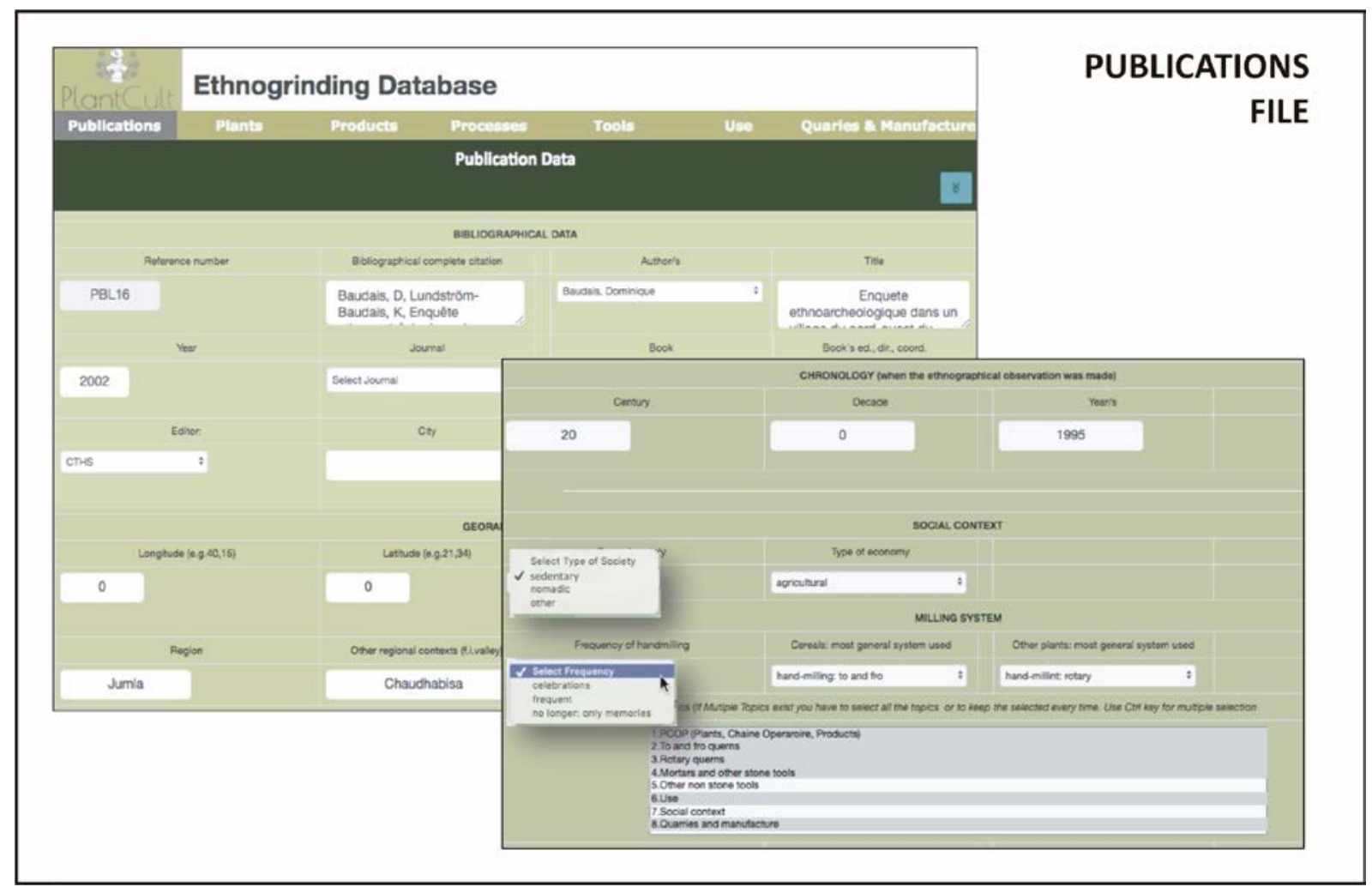

Figure 3. The Publications tab.

This tab also serves to collect geographic and ethnic data (continent, country, region, town, village and ethnic group), the timeframe of the ethnographic observation (century, decade and year), as well as the social context and grinding system in place at the moment of the observations. In addition, when available, the community's socio-economic context is described. This refers to whether the society is nomadic or sedentary, and whether their economy is based on hunting-gathering or agriculture.

Finally, the tab offers a description of the grinding system in use today and the frequency of manual grinding. It also details if the milling is habitual or restricted to special occasions (such as celebrations), or if it is no longer in practice and, therefore, only in collective memory. The milling systems tab also offers the data as to whether the tools are intended for 
cereals and other plants, if the milling takes place outside the village, if the mill is electric, hydraulic or driven by hand, and if the mill is operated with a back and forth or rotary motion. Finally, the tab has a slot to add a short text summarising the publication's main points.

\subsubsection{Plants and other ingredients (Figure 4)}

The Publications tab is linked to a second tab labelled Plants that offers a detailed record of the types and species of plants and other raw materials processed for food. Since cereals make up the bulk of the published species, there is a specific menu offering a list of cereals and pulses. The other plants cited in the reviewed literature are acorns, oilseeds, peas, beans, coffee, garlic, peppers, etc. Finally, the listing also comprises other types of products such as meat, animal bones, dried fish, salt, pigments, roots for dyes, and clay and temper for pottery manufacture.

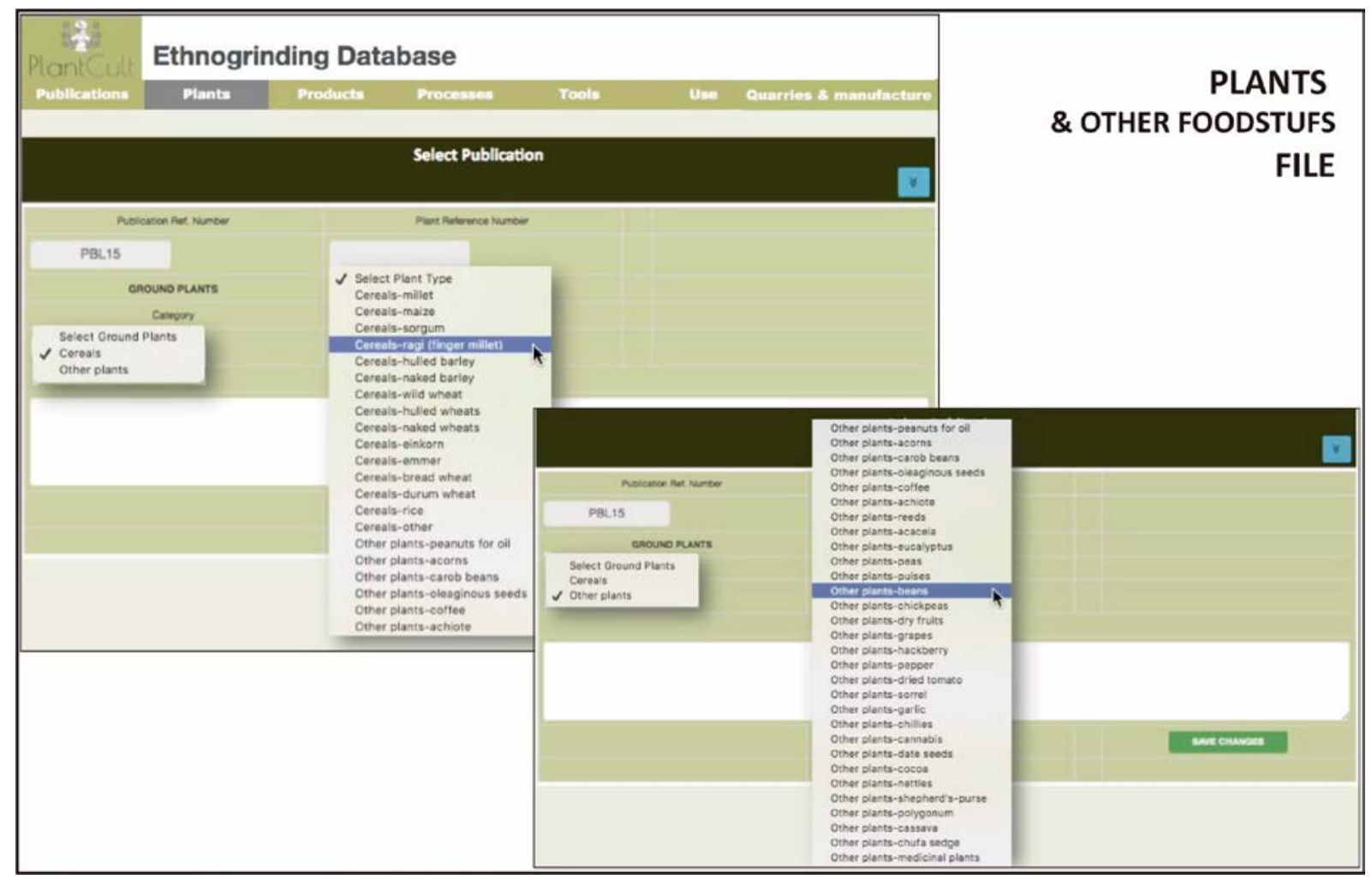

Figure 4. The Plants tab.

\subsubsection{Processes (Figure 5)}

The Plants tab is followed by another, labelled Processes that offers the possibility to describe the milling process required by each plant according to its characteristics and the desired product. It is essential to collect this information in detail for the subsequent study of their relationship with the archaeological and archaeobotanical data (Alonso 2019). Three potential aspects are considered: pre-grinding grain treatments, operations prior to grinding, and the operational sequence of grinding. Drying, roasting, soaking and boiling are the main initial treatments of grains. Operations prior to milling include washing, drying, dekerneling, dehusking, sieving, winnowing, hand cleaning, bran separation, boiling and rinsing. In addition to listing these tasks, this tab permits their description and recording so as to include the technique and tools. Likewise, the grinding operational sequence is added when identified in the publication. This includes specifications of all the products at each stage of the 
sequence. The final products of the process are often multiple and accompanied by derivatives or by-products.

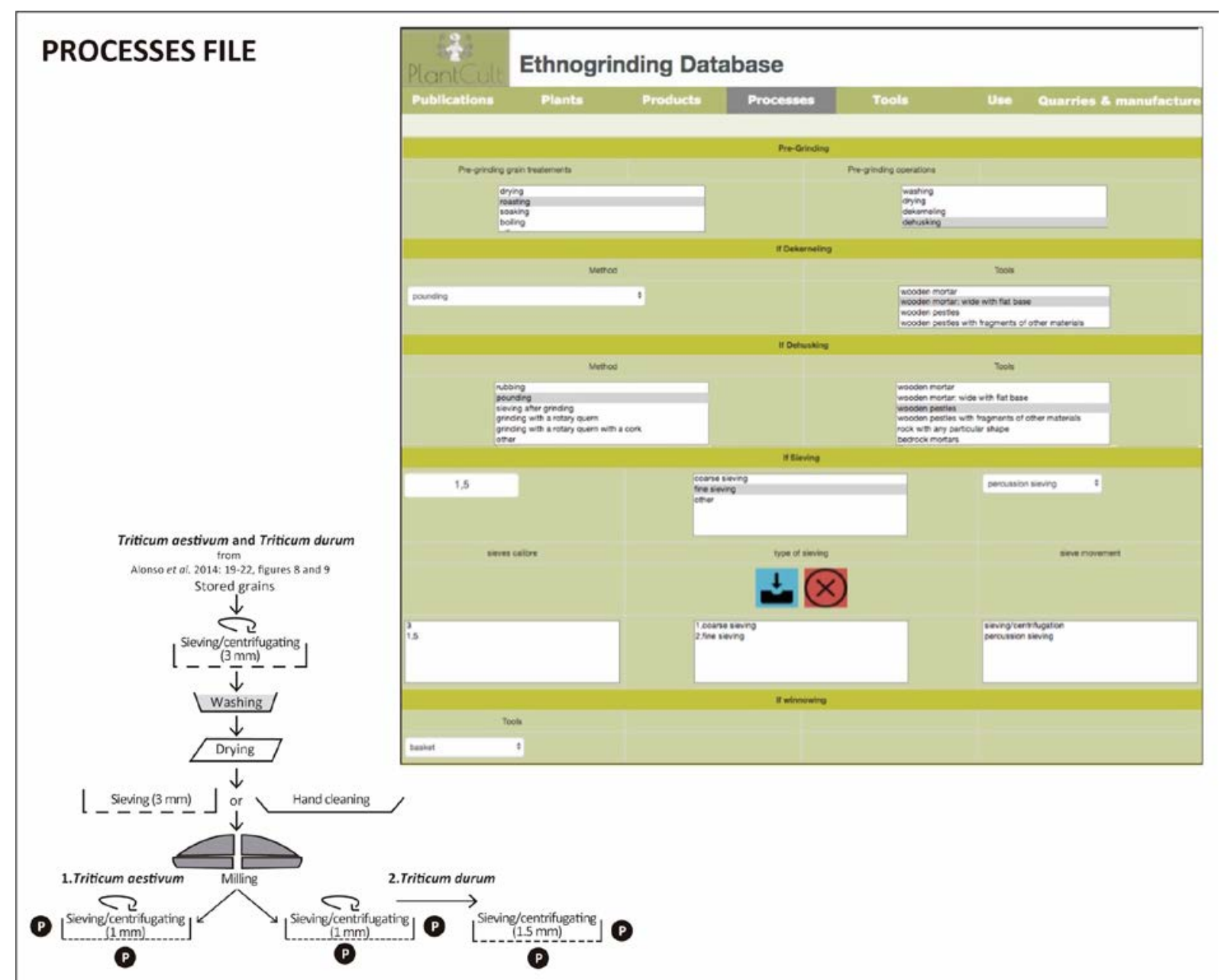

Figure 5. The Processes tab and an operational sequence of processing naked wheats according to Alonso et al. 2014.

\subsubsection{Products (Figure 6)}

Although the interface does not pretend to offer an exhaustive collection of culinary products, it is nonetheless essential to register all the products resulting from the grinding and cooking process in the Products tab when they are specified in the publications. Hence when a publication refers to these products they are identified and given a registration number as in the case of the other aspects.

Yet, as specified in the tab, a different series of types of final products can be yielded from a grinding sequence. To begin with, the product's caliber is classified into different categories: flour, coarse groats, fine groats, fine semolina, bulgur, dough and split pulses. These, in turn, can serve for a number of different foods that are grouped into the following categories of products and dishes: cereal foods, beverages and beers, sauces and condiments, and medicines. Among the first category is bread, flatbread, porridge, soup, couscous, pasta, trachana, fava and biscuits. Beer and other beverages are divided into fermented grains, sprouted grains, malt and syrup. Finally, the tabs of sauces, condiments and medicines remain open due to their wide variety.

The database also takes into account other aspects such as cooking methods (baked, boiled or steamed), fuel type (manure, wood, coal or twigs), and description of the context of 
consumption (i.e., daily or ceremonial). Although the recording of these aspects is not one of the main objectives, their relationship and their future connections are important to databases on old written sources, archaeological mills and the spaces where food preparation took place.

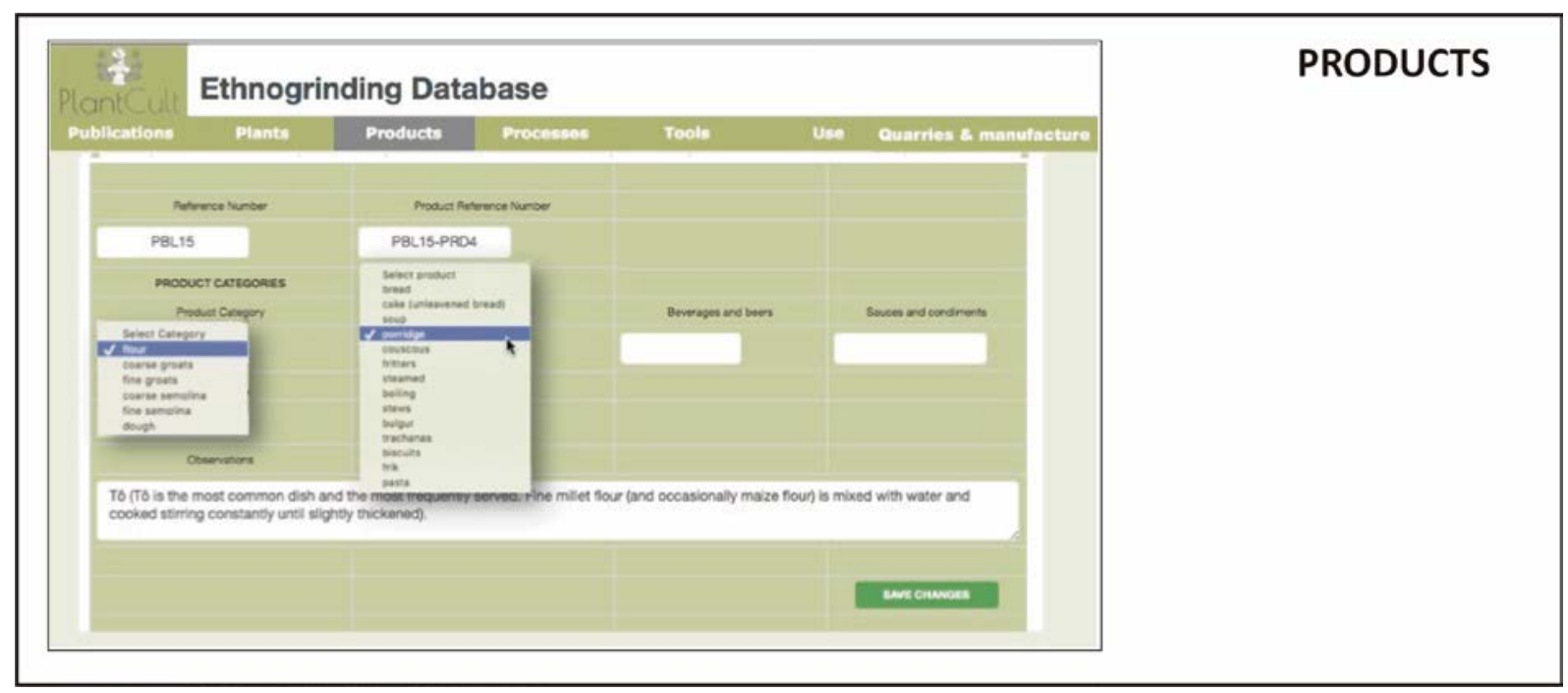

Figure 6. The Products tab.

\subsubsection{Tools (Figure 7)}

The tab regarding the different types of mills focuses mainly on querns driven with a back and forth movement since these, at least for the moment, are the prehistoric mills of reference of the PLANTCULT project. Data regarding mills in the Tools tab is classified into two categories: initial or modified properties (modified by use). The data also includes the option of a description of the mill's last life cycle and possible secondary uses after breakage, obsolescence, discarding or abandonment.

The first data regards the initial properties of the quern's passive (lower) and the active (upper) stones: raw material, dimensions and general morphology. The item of raw material includes lithology and granularity (fine or coarse) as indicated by the authors of publications. Likewise, there is the option to specify if the two stones of each mill are of the same lithology or not, and if not, the motive for the difference.

Regarding the mill's general morphology, the upper stone falls into three general types: Type 1 (the length of the upper surpasses the width of the lower, i.e., "overlapping type"), Type 2 (the length of the upper is less than the width of the lower) and Type 3 (the upper is small). These three general types coincide with those serving as reference in the experimental program of the PLANTCULT project, although other more diverse and detailed typologies can subsequently be added. A section of this tab also is dedicated to determining the traces of usewear. Finally, the previous typological notions are completed by formal measurements of both the face and sections (rectangular, oval, etc.) of each of the mill's stones.

Secondly, the tab allows recording of the alterations affecting the rock, that is, all the aspects of its grinding surface and the data linked to wear and lifespan. The tab also permits recording the stone's sections, surface (pecked or polished), the position of polished surfaces and whether use-wear analyses were carried out. Regarding the question of the stone's lifespan, the tab allows recording the measurements of its useful life in years (maximum and average), if there is evidence of re-use as a grinder for other types of materials differing from its primary function, if it was transformed into another tool, and, finally, if the publication specifies its role after its life as part of a mill mechanism. 
Other tools besides querns described in publications can therefore be included in the database. Hence, when possible, the tab includes all the pertinent data related to mortars. That is, their type and main characteristics such as dimensions and raw material (wood or stone). Furthermore, the tab also permits recording whether the group under study also resorted to sieves, the material serving to make the sieves, and the calibre of their mesh. Finally, the tab offers the option to describe the types of pecking tools (stone or metal) serving to dress the surface.

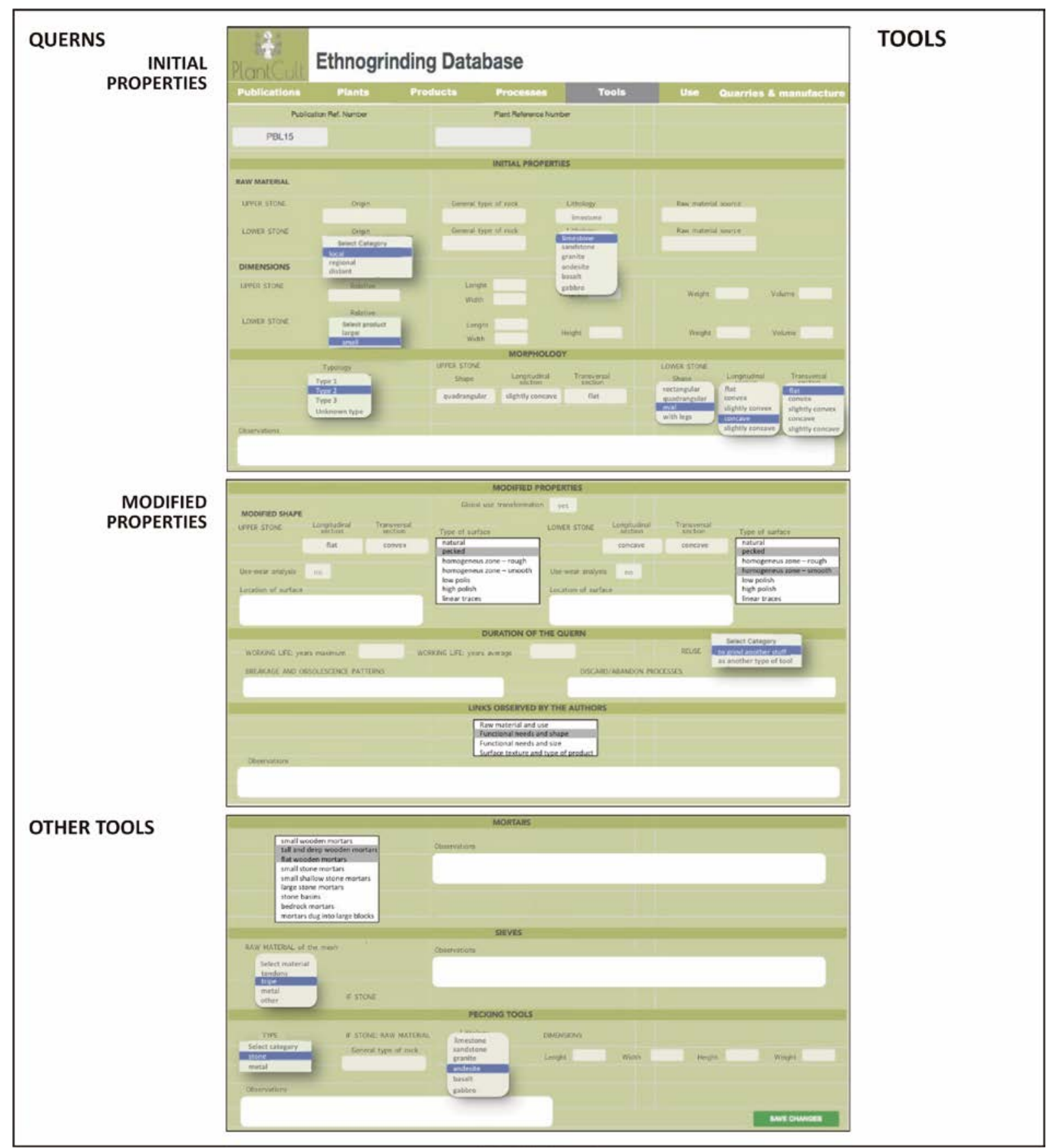

Figure 7. The Tools tab.

\subsubsection{Use and Social Context (Figure 8)}

The Use tab is designed to complete all information related to the use of mills and their social context. It offers the option to record different aspects of what can be called the 
"milling fact" such as if the mill is portable or fixed, and of great interest, if it is placed at floor level or raised (slightly or very much higher) on a structure. In the case of the latter, the tab allows noting if the structure is, for example, a table, tripod or plastic drum, as well as whether it served for a single or multiple mills. In the second case, it allows noting the number of mills. Likewise, there is a field to describe the nature of the grinding surface (flat or inclined), and if inclined, how the inclination is achieved (by placing a stone under one side, for example, or simply by the mill's own morphology).

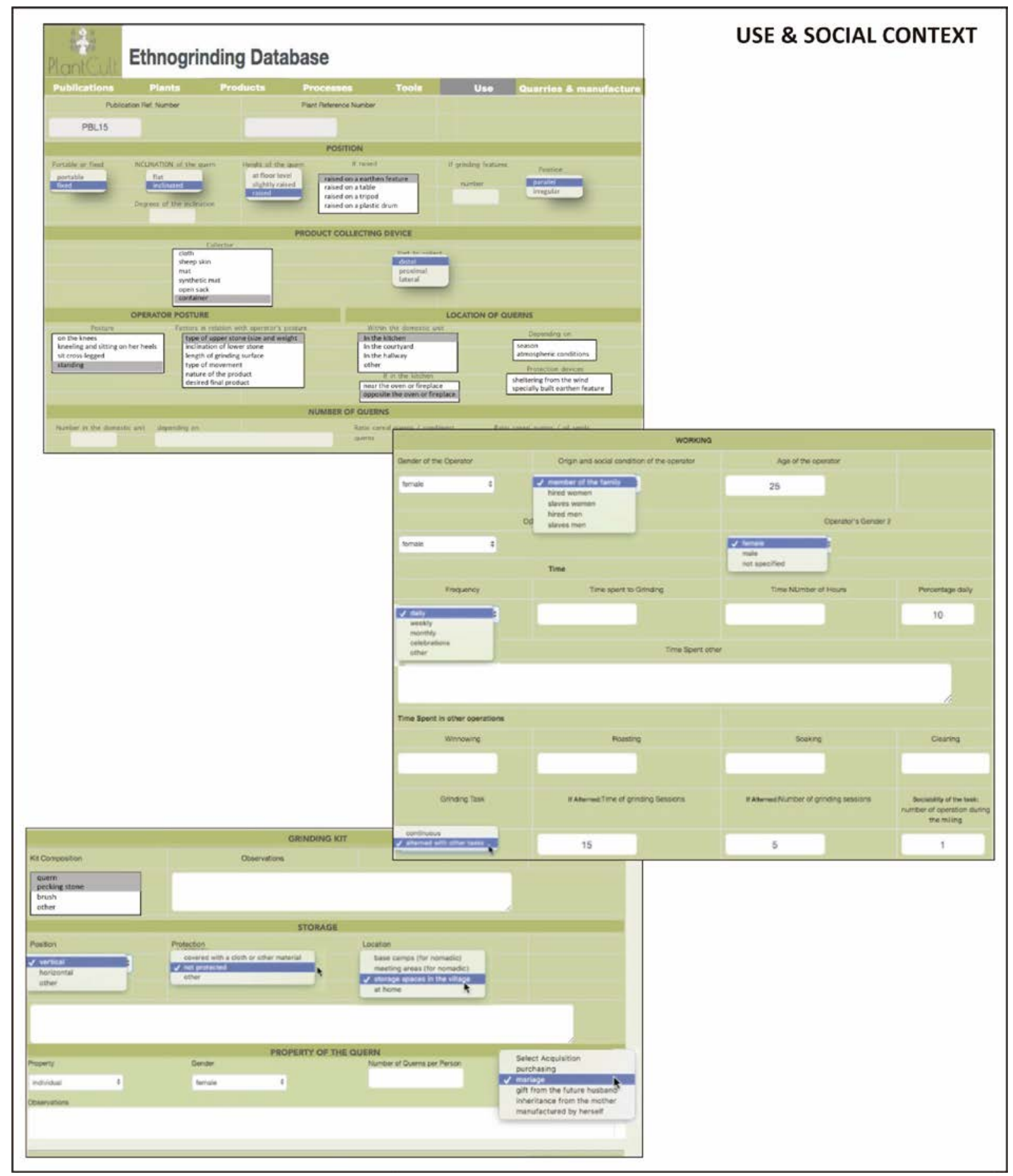

Figure 8. The Use tab. 
Furthermore, the tab allows indicating the presence and type of device serving to gather the flour or other product that accumulates around the mill during grinding. "Flour catchers" include cloths, sheepskins, rugs, synthetic rugs, open sacks or containers. To be more specific, the field allows to specify how and where the product is collected, and if the feature is placed along the mill's distal or lateral section.

There is also a field pertaining to the position adopted by the mill operator: squatting, sitting on one's heels, sitting cross-legged or standing, as well as the evidence indicating the position, to wit, the type of upper stone (size and weight), the inclination of the lower stone, the length of the grinding surface, the type of movement, the nature of the product or the desired final product.

The next tab concerns the location of the mills in the domestic unit, for example, in the kitchen, the patio or corridor. If in the kitchen, then there is the question if it is near or opposite the oven or hearth, the why of its location, and if the mill benefits from protective devices. Finally, the number of household mills is noted if specified in the publication and the relationship between cereal mills and other types of tools dedicated to other products such as condiments or oil.

Other noteworthy aspects linked to the social context are data as to the mill operator and related tasks. This tab records the gender, age, origin and social status, as well as if other operators participate in the process. In addition, the tab provides a field to enter the frequency of grinding (daily, weekly, monthly, or only during celebrations), as well the amount of grinding time (number of hours or the percentage of the day). Yet the project does not limit itself strictly to the question of grinding time as it takes into consideration the time dedicated to related operations such as grain cleaning, soaking and roasting. The tab then offers the opportunity to indicate if the milling was a continuous operation or if it was alternated with other tasks. There are, in the case of this last option, tabs to specify the length and number of sessions, as well as the level of the task's sociability, that is, the number of participants.

Finally, the tab permits recording of all the aspects related to pounding and crushing linked for the most part to issues of sociability and location of the task (e.g., inside or outside the settlement). In addition, it allows recording the content of grinding "kits" (e.g., millstones, pecking tools to dress the grinding surface and brushes for cleaning), and data on mill ownership and storage between use. Ownership can be broken down into individual or collective, owner gender, number of mills per individual, and means of obtaining. This last notion pertains to if the mills were manufactured by their owner, acquired from a specialist, obtained as a gift (e.g., marriage) or inherited (e.g., from mother). Finally, the question of mill storage requires taking into account several aspects such as millstone position (vertical or horizontal), potential protection (covered with a cloth or other material), and location (in the dwelling, in specific spaces within the village, or in base camps or meeting areas as is the case of certain nomadic societies).

\subsubsection{Quarries and manufacture (Figure 9)}

Although there is little ethnographic literature regarding quern quarries and their manufacture, this final tab briefly collects general notions of this nature. An important aspect is to determine, if possible, the quarry type (according to the millstone quarry typology proposed by Timothy Anderson in 2016) and where the final stages of millstone manufacture are carried out (in the quarry, village or elsewhere). Also, along the lines of the social context of millstone making, the tab offers the possibility to record the operational sequence and the tools of manufacture. Finally, the types of tasks carried out by either men or women can be specified. These include, for example, the choice of the raw material, its procurement, and the initial or final stages of production. 


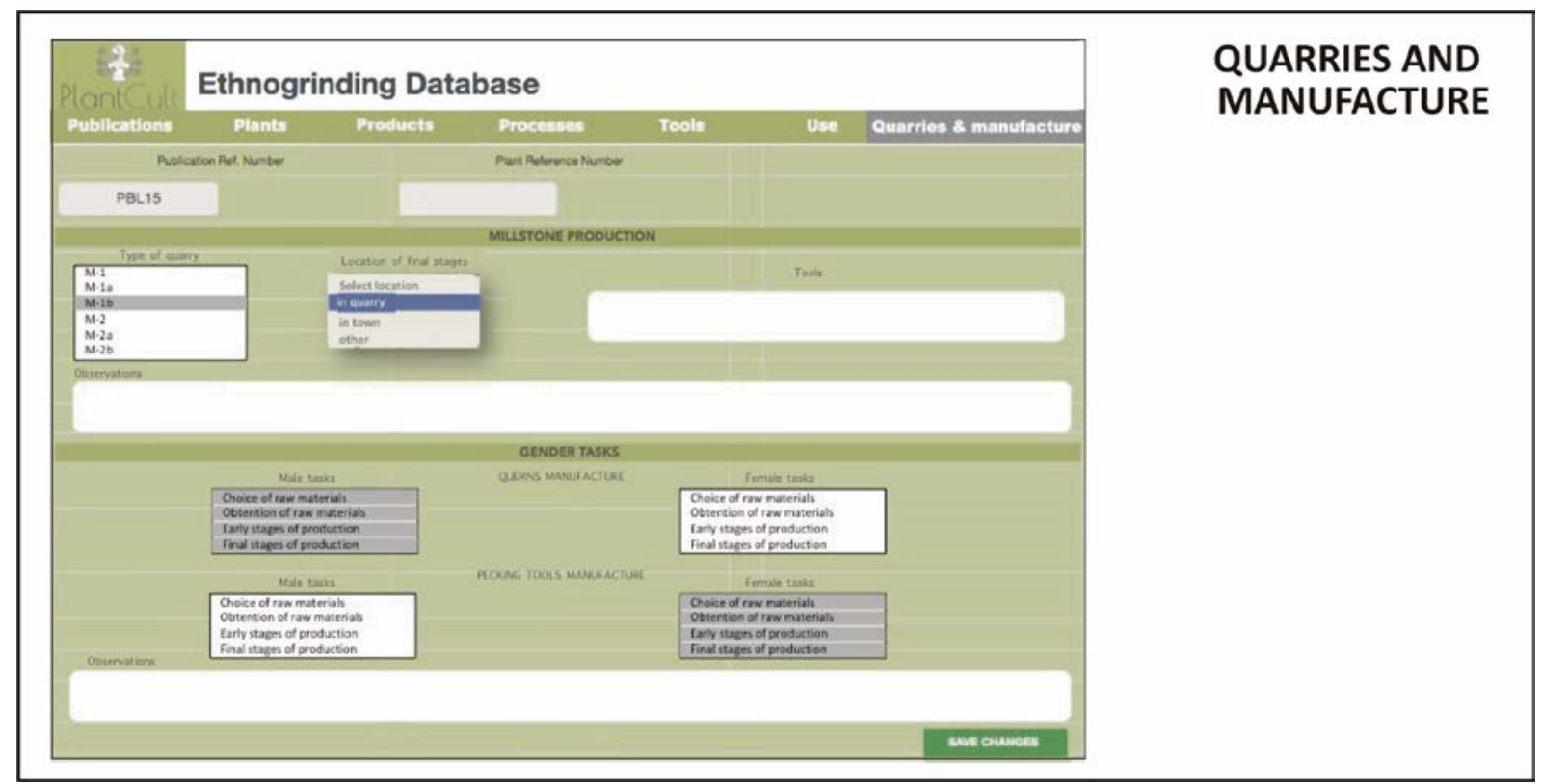

Figure 9. The Quarries and Manufacture tab.

\subsection{Bibliographic research on ethnographic grinding tools}

\subsubsection{Bibliographic and documentary resources}

One of the most relevant activities carried out in the framework of the project is the compilation of diverse bibliographic references published throughout the world linked to grinding processes and tools. The study has focused initially on online resources, which has led to consultation of many online and paper archaeological, anthropological and ethnographic journals. The project also carried out searches through the following platforms: Academia.edu, ResearchGate, Springer Link and JSTOR. Likewise, certain resources were accessed exclusively online such as the Online Archive of California or the catalogue of the Biblioteca Nacional de Antropología e Historia "Dr. Eusebio Dávalos Hurtado” (BNAH) of the National Museum of Anthrolopology of Mexico.

Secondly, searches were carried out in the Libraries of the University of Lleida and the Aristotle University of Thessaloniki. Images from old publications of these types of subjects are depicted on a wide range formats (plates, engravings and photographs) that also form part of the interface.

In sum, the resources are classified into different categories: books, journal articles (the majority), doctoral theses, conference proceedings and images from archives. The publications basically contain ethnographic data from primary sources, that is, ethnographic or ethnoarchaeological analyses carried out by the authors themselves. Surveys compiling information gleaned from other sources, although rich in information, were generally discarded. Certain were nonetheless retained as they comprise information from publications that are difficult to access. The specific publications worth highlighting are summarised in Table 1.

Moreover, all the references collected so far, which have resulted in a large volume of information, were systematised in a database created exclusively for the bibliography of the project. Each article or book is identified with a reference number that simultaneously serves in the ethnographic database cited above. The bibliographic field includes the following tabs: author(s), year, title, magazine name, number, pages, complete publication, summary, keywords, chronology, continent, country, region and ethnic group. In short, it is an essential 
and user-friendly bibliographic database whose main functions are to record and organise publications, streamline the search process and highlight specific and relevant aspects.

Table 1. The main bibliographic resources consulted about handmills and their uses.

\begin{tabular}{|c|c|}
\hline CATEGORIES OF RESOURCES & PUBLICATIONS \\
\hline Conference Proceedings & $\begin{array}{l}\text { Procopiou \& Treuil (2002); Barboff et al. (2003); } \\
\text { Gelbert (2005); Williams \& Peacock (2011) }\end{array}$ \\
\hline Ethnoarchaeological Monographs & Tombul (2005); Hayden (1987); Searcy (2011) \\
\hline Archaeological Monographs & Adams (2002); Selsing (2014) \\
\hline Scientific Journals & $\begin{array}{l}\text { Journal of Anthropological Archaeology; American } \\
\text { Anthropologist; American Ethnologist; Australian } \\
\text { Aboriginal Studies; The Artefact; Ethnologia } \\
\text { Europaea; Kiva; The Journal of Southwest } \\
\text { Anthropology and History; Archaeological and } \\
\text { Anthropological Sciences; Current Anthropology; } \\
\text { Ethnographisch-Archäologische Zeitschrift; Journal } \\
\text { des africanistes; African Archaeological Review }\end{array}$ \\
\hline Doctoral Theses & $\begin{array}{l}\text { Ertug-Yaras (1997); Teklu (2012); Nixon-Darcus } \\
\text { (2014) }\end{array}$ \\
\hline
\end{tabular}

\subsubsection{Preliminary analysis}

The database, to date, comprises 160 publications. There exist, nonetheless, many more publications on this subject. The next section of this paper constitutes a first assessment of the data based on ethnographic milling processes and mills. The types of documents, as noted above, comprise all forms of ethnographic, ethnoarchaeological and archaeological publications. It is noteworthy that the interface is dominated by ethnoarchaeological and ethnological publications while archaeological records remain a minority.

On the one hand, there exists a remarkably large number of archaeological studies recurring to ethnographic mills and milling processes for comparative purposes. Ethnohistoric records are thus essential to developing models of the past. They also assist in formulating working hypotheses that go beyond archaeological observations, and serve as a basis for experimental archaeology (Nesbitt \& Samuel 1996). Likewise, archaeologists profit from ethnographic and ethnohistorical experimental work to interpret archaeological data.

Moreover, as noted previously, published ethnoarchaeological and ethnological research (including ethnobotany) make up the largest data set. In fact, these publications contain the most specific data linked to the project's objectives. Actually, only a few strictly ethnoarchaeological or ethnographic works relate to all or most of the database's variables. Encompassing all the data is a complex task. In this sense, certain studies, some carried out by archaeologists, do take into account many aspects of the database (Roux 1985; David 1998; Ertug-Yaras 2002; D’Andrea \& Haile 2002; Baudais \& Lundström-Baudais 2002; Gelbert 2005; Tombul 2005; Peña-Chocarro et al. 2009; Searcy 2011; Teklu 2012; Hamon \& Gall 2013a; Alonso et al. 2014; Nixon-Darcus \& D’Andrea 2017).

On the other hand, noteworthy among the ethnographic research are the publications Land, labour and diet in northern Rhodesia (Richards 1939) and Alimentation des populations de l'Ahaggar, Étude ethnologique (Gast 1968). The project has also taken into account publications that, although not dealing with issues strictly related to ethnographic grinding processes, may offer interesting data. There are, for example, gender studies that 
attempt to identify the participation of women and their roles throughout Prehistory and History such as Gero \& Conkey (1991). In addition, there are ethnobotanical publications such as the Journal of Ethnobiology or the book by Fairbairn \& Weiss (2009) that include studies of related subjects.

The current state of the database indicates that the geographical areas yielding most of the ethnographic observations are America and Africa (each 29\%). These are followed by Asia (22\%), Oceania (10\%) and Europe (9\%). More specifically, the North and East of Africa (mainly Ethiopia and Sudan) are the regions with the greatest number of studies followed by the southwest of North America, the Near East, Meso-America, and Australia. In fact, research carried out in Turkey is worth highlighting as comparative analogies deriving from ethnological observations of current communities applied to past cultures has a long history in Anatolia. In addition, worthy of mention is the large volume of Meso-American research on grinding processes and their social context, and on the manufacture of the mills (metates and manos). Figure 10a identifies the areas where these types of studies have been carried out.

With respect to ethnicity, the project has registered, to date, approximately 20 groups with the largest number spread throughout the African continent. The numerous ethnic studies of North and Meso-American cultures are also worth highlighting.

The main topics among the bibliographic sources are the mills themselves (regardless of type), plants, grinding processes and other implements. As to the description of tools, most of the publications focus on millstones, specifically on querns driven with a back and forth movement, to the detriment of watermills, windmills and rotary querns. Furthermore, handdriven rotary querns are rarely cited in more general studies except those by Parton (2011) and Alonso et al. (2014). It must be emphasised that the descriptions remain, nonetheless, generic without delving into the details of their characteristics. The articles delve into rotary quern morphology and at times specify their dimensions and general notions of lithology, leaving aside, for example, the shape and the state of the grinding surface. It is also worth mentioning that in the case of mill types on the whole, lower stones are more often described than upper stones. To conclude, it is worth highlighting that it is more common to find references to cereal mills than to mills serving for other products such as condiments, salt or pigments (with some exceptions, e.g., Aschmann 1949; Davidson \& McCarthy 1957; De Beaune 1989; Euler \& Dobyns 2012; Gifford 1936; Gould et al. 1971; Hamon \& Le Gall 2013a; Kramer 1982;). Furthermore, there are also references to other implements serving in the grinding process (or other tasks) such as mortars and pestles whose use in conjunction with mills also is the object of description as part of the milling sequence (e.g, Ertug-Yaras 2002; Hamon \& Le Gall 2013a; Hillman 1984; Peña-Chocarro et al. 2009; Teklu 2012).

With regard to plants and other processed materials, the current state of the database reveals that the importance of each is distributed according to geographical zones and, obviously, whether the economy of their societies are based on farming or hunter-gathering (Figure 10b). In the Mediterranean-Europe (comprising all the countries of the Mediterranean, Europe, the Near East and North African, including Ethiopia). East Asia and Africa zones wild plants are seldom or rarely cited. Cereals are the most important plants: hulled wheats and hulled barley in the first zone, corn, millet and sorghum in Africa and millet especially in Asia. Other cultivated plants such as pulses are most commonly cited in Asia and the Mediterranean (in the latter also dry tomato, onion, potato or pepper), whereas medicinal plants or wild oleaginous in Africa are also usually processed (e.g., D’Andrea \& Haile 2002; Casajus 1987; Delgado-Raack \& Risch 2009; Ertug-Yaras 1997; 2002; Gast 1968; Hamon \& Le Gall 2013a; Lundström-Baudais et al. 2002; Peña-Chocarro 1996; Roux 1985; Teklu 2012; Valamoti 2011). Cultivated plants in America are also the most frequently cited, although a wide variety of wild plants is also processed (oleaginous, medicinal plants, acorns). Corn is clearly the "star" cereal followed by legumes and other cultivated plants 
(tobacco, sugar, coffee) (e.g., Adams 1988; Babot 1999; Capparelli \& Lema 2011; Hayden 1987; Horsfall 1987; López et al. 2011; Mauldin 1993; Searcy 2011; Stephen 1936).
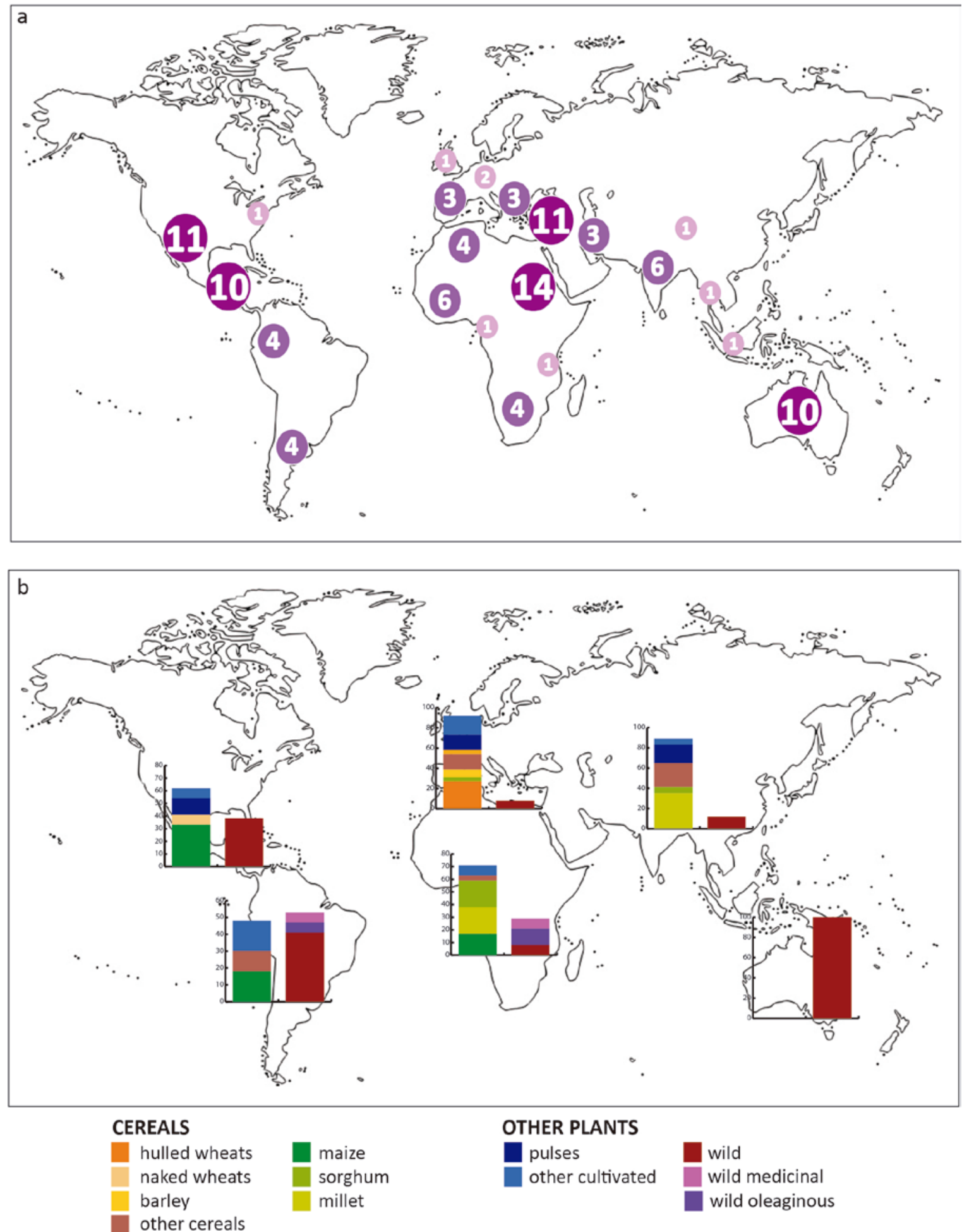

Figure 10. (a) Geographic zones with published ethnographic and ethnoarchaeologic studies that include data about grinding systems and their percentage (in the current state of the databse); (b) Percentage of citings of types of plants in the publications consulted to date in the following zones: southeast of North America and Meso America; South America; Europe and Mediterranean countries (plus Ethiopía); central and oriental Asia; Australia. 
Finally, the indigenous societies of Australia are hunter-gatherers, mainly generalists, that characteristically exploited and processed a wide variety of wild plants (wild cereals, wild legumes) in mills and mortars (e.g., Bindon 1996; Cane 1989; Gott 1999; Heidi \& Wallis 2012; Jones \& Meehan 1989).

The grinding process in the framework of techniques is only the object of general descriptions in the different studies. It is noteworthy that among the different tasks and treatments before and after grinding (see Processes), grain dehusking and its specific tools are often the object of a detailed description (e.g., D'Andrea \& Haile 2002; Hamon \& Le Gall 2013a; Mawadza et al. 1999; Peña-Chocarro 1996; Peña-Chocarro et al. 2009). Hence, it is normal that the tools most often cited, apart from mills, are mortars and pestles (although without differentiating their type), as noted previously, as they are the most appropriate means of dehusking (e.g., Harlan 1967; Hamon \& Le Gall 2013b; Hillman 1981). However, the narrative of this process usually does not include a description of the individual that carries out the task.

Finally, there are a few publications that refer to the question of the type of products yielded by the different milling tasks in the final stages of the process (e.g., Hamon \& Le Gall 2013a; Hilman 1981; Klmata et al. 2000; Peña-Chocarro et al. 2009; Simango 1997; Valamoti 2011). Although in certain cases these are identified, they are rarely analysed in depth. The same occurs in references to in the references to use and social context, that is, how milling was carried out, who owned the mills, the position adopted by their operator, etc. Finally, there is also little information regarding quern and millstone quarries, raw materials, and their tools and manufacturing processes, trace-wear analyses and the question of the wear of grinding surfaces (e.g., Aschman 1949; Anderson 2016; Davidson \& McCarthy 1957; Hamon \& Le Gall 2011).

In short, this first analysis of how the data from publications are described and presented leads to a deeper understanding of the type of information at hand.

\section{Conclusion}

This paper attempts to advance the two main axes of ethnographic research on milling tools and milling processes within the framework of the PLANTCULT project: bibliographic research and an ethnographic database. In the first place, it is essential to emphasise that ethnographic research offers the project direct information on the different means of transforming plants into food, an aspect closely related to culinary practices, culinary identities and socio-economic relationships.

Hence, the scope of the database is not restricted strictly to the interests of archaeologists and archaeologists specialised in mill research. The information collected is of interest also to ethnographers and archaeologists of various specialities who will be able to access directly a number of original works in search of more information. Surely many archaeologists, for example, will be surprised by the complexity and breadth of economic and social connections of mills, a type of artefact that is often undervalued in archaeological research. Numerous links, in fact, can be established between the study of archaeological mills and information yielded in publications in the database. There is, for example, the question of the characteristics of the mills (raw material, morphology, wear, dimensions) and their situation in a site (e.g., location in the settlement or the house), their use of plants and their exploitation in quarries.

It must be highlighted that the current presentation is preliminary - a work in progress as well as an essential aspect of the project. Moreover, since the search for bibliographic references is an ongoing task, the documents currently forming part of the database will be expanded in the future. In sum, the research is based on a number of bibliographic and 
documentary resources from libraries - and above all from online platforms. Ethnographic and, mainly, archaeological and ethnoarchaeological studies make up the bulk of the tabs. The geographical areas of the ethnographic research that stand out are northern and eastern Africa, southwestern North America, Meso-America, Australia, and Turkey. The subjects most often addressed in the bibliographic sources, from highest to lowest, are querns, plants and products, milling operations, tools used in parallel with the querns, the use of tools and processed products, and finally, references to social context, lithology, quarries, manufacture and use-wear.

It must also be taken into account that the aspects advanced in this article were reasoned previously during the development of the database, and more so during the initial research carried out by Alonso (2019). With the introduction of the bibliographic data certain concepts and aspects can be modified, improved, changed and extended. Hence the database is a dynamic working tool in continuous motion adapted to the needs of research, and subject to information gleaned from emerging documentary sources. In short, as data collection and input expands, the number of topics will grow and new elements will surge.

Moreover, the interface advanced in this paper was developed to accept updates. A future feature is a tool to consult and extract data. Ultimately, upon conclusion of the project, the database will be available on the PLANTCULT project website (www.plantcult.web.auth.gr).

\section{Acknowledgements}

This research has been funded by the European Research Council (ERC), in the context of Project "PLANTCULT Identifying the Food Cultures of Ancient Europe", conducted under the European Union's Horizon 2020 Research and Innovation Program (Grant Agreement no. 682529), Consolidator Grant 2016-2021. Natàlia Alonso's contribution is also within the framework of projects HAR2016-78277 and SGR2017-1714. We thank Maria Bofill for her valuable input during the preparation of the data base fields.

\section{References}

Adams, J. L. 1988, Use-Wear Analyses on Manos and Hide-Processing Stones. Journal of Field Archaeology, 15(3): 307-315. doi:10.2307/530311

Adams, J. L. 2002, Ground Stone Analysis: A Technological Approach, University of Utah Press, $334 \mathrm{p}$.

Alonso, N. 2019, A First Approach to Women, Tools and Operational Sequences in Traditional Manual Cereal Grinding. Archaelogical and Anthropological Sciences, 11(8), 4307-4324. doi:10.1007/s12520-019-00791-x

Alonso, N., Cantero, F. J., Jornet, R., López, D., Montes, E., Prats, G. \& Valenzuela, S. 2014, Milling Wheat and Barley with Rotary Querns: The Berber Ouarten Women (Dahmani, El Kef, Tunisia). In: Seen through a millstone. Geology and archaeology of quarries and mills (Selsing, L, Ed.), Museum of Archaeology, University of Stavanger, Bergen, p. 193-212.

Anderson, T. J. 2016, Turning Stone to Bread: A Diachronic Study of Millstone Making in Southern Spain, Southampton Monographs in Archaeology No. 5, The Highfield Press, Southampton, $341 \mathrm{p}$.

Antolín, F., Alonso, N., Berihuete, M., Brombacher, Ch., Chondrou, D., Ertug, F., GarcíaGranero, J.J., González-Carretero, L., Hamon, C., Heiss, A.G., Jacomet, S., Naranjo, Y., 
Perego, R., Procopiou, H., Steines, B., Valamoti, S., Wojtczak, D., Wollstonecroft, M. 2016, Grütze, Bulgur, Mehl un Griess, Jahrbuch Archäologie Schweiz, 99: 143-151.

Aschmann, H. 1949, A Metate Maker of Baja, California. American Anthropologist, 51(4): 682-686. doi:10.1525/aa.1949.51.4.02a00350

Babot, M.P., 1999, Recolectar para moler. Casos actuales de interés arqueológico en el Noroeste Argentino, In: En los tres reinos: prácticas de recolección en el cono sur de América (Aschero, C. A., Korstanje, M. A. \& Vuoto, P. M. Eds.), Ediciones Magna Publicaciones, San Miguel de Tucumán, p. 161-170.

Baudais, D. \& Lundström-Baudais, K. 2002, Enquête ethnoarchéologique dans un village du nord-ouest du Népal: les intruments de mouture et de broyage. In: Moudre et Broyer. L'interprétation fonctionnelle de l'outillage de mouture et de broyage dans la Préhistoire et l'Antiquité, Vol. 1: Méthodes (Procopiou, H. \& Treuil, R., Eds), CTHS, Paris, p. 155-180.

Barboff, M., Sigaut, F., Griffin-Kremer, C. \& Kremer, R. (Eds) 2003, Meules à grains. Proceedings of the International Colloquium of La Ferté-sous-Jouarre, 16 -19 may 2002. Éditions Ibis Press. Éditions de la Maison des Sciences de l’Homme, 480 p.

Bindon, P. 1996, Useful Bush Plants. Western Australian Museum, Perth, 286 p.

Cane, S.1989, Australian Aboriginal seed grinding and its archaeological record: A case study from the Western Desert. In: Foraging and farming: The evolution of plant exploitation (Harris, D.R. \& Hillman, G.C., Eds.), Unwin Hyman, London, p. 99 - 119.

Capparelli, A. \& Lema, V. 2011, Recognition of post-harvest processing of algarrobo (Prosopis spp.) as food from two sites of Northwestern Argentina: an ethnobotanical and experimental approach for desiccated macroremains. Archaeological and Anthropological Sciences, 3(1): 71 - 92. doi:10.1007/s12520-011-0052-5

Casajus, D. 1987, La Tente dans la solitude. La société et les morts chez les Touaregs Kel Ferwan, Éd. de la Maison des Sciences de l'Homme, Paris, 392 p.

D’Andrea, A. C. \& Haile, M. 2002, Traditional emmer processing in highland Ethiopia. Journal of Ethnobiology, 22(2): 179-217.

David, N. 1998, The ethnoarchaeology of grinding at Sukur, Adamawa state, Nigeria. African review, 15: 13-63.

Davidson, D.S. \& McCarthy, F.D. 1957, The Distribution and Chronology of Some Important Types of Stone Implements in Western Australia. Anthropos, Bd. 52, H. 3./4: 390-458.

De Beaune, S.A. 1989, Essai d'une classification typologique des galets et plaquettes utilisés au Paléolithique, Gallia Préhistoire, 31(1): 27 - 64. doi:10.3406/galip.1989.2264

Delgado-Raack, S. \& Risch, R. 2009, Towards a systematic analysis of grain processing technologies. In: Recent functional studies on non-flint stone tools: Methodological improvements and archaeological inferences, 23-25 May 2008 (Igreja, M. \& Clemente, I., Eds).

URL: https://grupsderecerca.uab.cat/asome/sites/grupsderecerca.uab.cat.asome/files/del gado_risch_2009.pdf

Ertug-Yaras, F. 1997, An Ethnoarchaeological study of subsistence and plant gathering in central Anatolia. PhD Thesis, Washington University, 425 p. 
Ertug-Yaras, F. 2002, Pounders and Grinders in a Modern Central Anatolian Village. In: Moudre et Broyer. L'interprétation fonctionnelle de l'outillage de mouture et de broyage dans la Préhistoire et l'Antiquité, Vol. 1: Méthodes (Procopiou, H. \& Treuil, R., Eds), CTHS, Paris, p. 211-227.

Euler, R., \& Dobyns, H., 2012, The Ethnoarchaeology Of Pai Milling Stones, Journal of California and Great Basin Anthropology, 32(2): 197-201.

Fairbairn, A. \& Weiss, E. (Eds), 2009, Ethnobotanist of distant pasts: Archaeological and ethnobotanical studies in honour of Gordon Hillman, Oxbow, Oxford, 298 p.

Gast, M. 1968, Alimentation des populations de l'Ahaggar. Étude ethnographique. Mémoires du Centre de Recherches Anthropologiques Préhistoriques et Ethnographiques Vol. 8, Paris, $457 \mathrm{p}$.

Gelbert, A. 2005, Evolutions du matériel de broyage dans la communauté Dii de Djabe (Nord-Cameroun) durant les deux derniers siècles (Études ethno-archéologiques et archéologiques). In: Ressources vivrières et choix alimentaires dans le bassin du lac Tchad (Raimond, C., Langlois, O. \& Garine, E., Eds.), IRB Éditions, Prodig Éditions, Paris, p. 319-347.

Gero, J. M. \& Conkey, M. W. (Eds) 1991, Engendering Archaeology: women and prehistory, Blackwell, Oxford, 436 p.

Gifford, E.W., 1936, Northeastern and Western Yavapai. University of California Publications in American Archaeology and Ethnology, Berkeley, 34 (4): 247-354.

Gott, B. 1999, Cumbungi, Typha species, a staple Aboriginal food in southern Australia, Australian Aboriginal Studies, 1: 33-50.

Gould, R. A., Koster, D. A. \& Sontz, A. H. L. 1971, The Lithic Assemblage of the Western Desert Aborigines of Australia. American Antiquity, 36(2): 149 - 169. doi:10.2307/278668

Hamon, C. \& Le Gall, V. 2011, Les meules en pays Minyanka (Mali): étude des carrières et techniques de production actuelles, In: Bread for the People: The Archaeology of Mills and Milling. Proceedings of a Colloquium held in the British School at Rome 4th - 7th November 2009 (Williams, D., Peacock, D. Eds.), BAR International Series Vol. 2274, Archaeopress, Oxford, p. 19-28

Hamon, C. \& Le Gall, V. 2013a, Millet and sauce: The uses and functions of querns among the Minyanka (Mali). Journal of Anthropological Archaeology, 32: 109-121. doi:10.1016/j.jaa.2012.12.002

Hamon, C. \& Le Gall, V. 2013b, Le végétal outil, le végétal transformé: fabrication et usages des mortiers en bois en pays Minyanka (Mali), In: Regards croisés sur les outils liés au travail des végétaux. An Interdisciplinary focus on plant-working tools, XXXIIIè Rencontres Internationales d'Archéologie et d'Histoire d'Antibes (Anderson, P.C., Cheval, C. \& Durand, A., Eds.), Éditions APDCA, Antibes, p. 267-278

Harlan, J. R. 1967, A Wild Wheat Harvest In Turkey. Archaeology, 20(3): 197-201.

Hayden, B. 1987, Lithic studies among the contemporary Highland Maya. The University of Arizona Press, Tucson, 387 p.

Heidi T. P. \& Wallis, L. A. 2012, The Point of Spinifex: Aboriginal uses of spinifex grasses in Australia. Ethnobotany Research and Applications, 10: 109-131. doi:10.17348/era.10.0.109-131 
Hillman, G. 1981, Reconstructing crop husbandry practices from charred remains of crops, In: Farming Practice in British Prehistory (Mercer, R., Ed.), Edinburgh University Press, Edinburgh, p. 123-162.

Hillman, G. 1984, Traditional husbandry and processing of archaic cereals in recent times: the operations, products and equipment that might feature in sumerian texts. Part I: the glume wheats. Bulletin on Sumerian Agriculture, 2: 114-152.

Horsfall, G.A. 1987, Design Theory and grinding stones. In: Lithic studies among the contemporary Highland Maya (Hayden, B., Ed.), The University of Arizona Press, Tucson, p. 332-377.

Jones, R. \& Meehan, B. 1989, Plant foods of the Gidjingali: ethnographic and archaeological perspectives from northern Australia on tuber and seed exploitation, In: Foraging and farming: The evolution of plant exploitation (Harris, D.R. \& Hillman, G.C., Eds.), Unwin Hyman, London, p. 120-135.

Kent, S. 1987, Method and theory for activity area research: an ethnoarchaeological approach, Columbia University Press, New York, 643 p.

Klmata, M., Ashok, A. \& Seetharam, A. 2000, Domestication, cultivation and utilization of two small millets, brachiaria ramosa and Setaria glauca (Poaceae), in South India. Economic Botany, 54(2): 217-227. doi:10.1007/BF02907825

Kramer, C., 1982, Village Ethnoarchaeology: Rural Iran in Archaeological Perspective, Academic Press, New York, 302 p.

López, L.M., Capparelli, A., Nielsen, A.E. 2011, Traditional post-harvest processing to make quinoa grains (Chenopodium quinoa var. quinoa) apt for consumption in Northern Lipez (Potosí, Bolivia): ethnoarchaeological and archaeobotanical analyses, Archaeological and Anthropological Sciences, 3: 49-70. doi:10.1007/s12520-011-00605

Lundström-Baudais, K., Rachoud-Schneider, A-M., Baudais, D., Poissonnier, B. 2002, Le broyage dans la chaîne de transformation du millet (Panicum miliaceum): outils, gestes et écofacts. In: Moudre et Broyer. L'interprétation fonctionnelle de l'outillage de mouture et de broyage dans la Préhistoire et l'Antiquité (Procopiou, H. \& Treuil, R., Eds), Vol 1: Méthodes, Éditions du CTHS, Paris, p. 181-209.

Mauldin, R. 1993, The relationship between ground stone and agricultural intensification in western New Mexico. KIVA, 58(3): 317-330. doi:10.1080/00231940.1993.11758212

Mawadza, C., Mpandi-Khosa, E., Zvauya, R., Gopo, J., Holzapfel, W. 1999, Microbiological changes in production of Mutwiwa, a fermented maize meal of Zimbabwe. Proceedings of the Regional Seminar on Traditional Fermented Food Processing in Africa, Accra, Ghana, July 1998, p. 34-42.

Nesbitt, M. \& Samuel, D. 1996, From staple crop to extinction? The archaeology and history of the hulled wheats. In: Hulled Wheat. Proceedings of the First International Workshop on Hulled Wheats, July 1995. Castelvecchio Pascoli, Tuscany, Italy (Padulosi, S., Hammer, K., Helle, J., Eds.), IPGRI, Rome, p. 40-99.

URL: https://www.bioversityinternational.org/fileadmin/_migrated/uploads/tx_news/Hu lled_wheat_54.pdf

Nixon-Darcus, L. 2014, The cultural context of food grinding equipment in Northern Ethiopia: an ethnoarchaeological approach, PhD Thesis, Simon Fraser University, 343 p. 
Nixon-Darcus, L. \& D’Andrea, A. C. 2017, Necessary for Life: Studies of Ancient and Modern Grinding Stones in Highland Ethiopia. African Archaeological Review, 34: 193-223.

Parton, H. 2011, The hand-mills of Olymbos: an ethnographical study of their form, function and role in a Greek village. In: Bread for the People: The Archaeology of Mills and Milling. Proceedings of a Colloquium held in the British School at Rome 4th - 7th November 2009 (Williams, D., Peacock, D. Eds.), BAR International Series Vol. 2274, Archaeopress, Oxford, p. 29-42.

Peña-Chocarro, L. 1996, In-situ conservation of hulled-wheat species: The case of Spain, In: Hulled wheats. Promoting the conservation and use of underutilised and neglected crops, Proceedings of the First International Workshop on hulled wheats (Padulosi, S., Hammer, K. \& Heller, J., Eds), IPGRI, Rome, p. 129-146.

Peña-Chocarro, L., Zapata, L., González, J.E. \& Ibáñez, J.J. 2009, Einkorn (Triticum monococcum L.) cultivation in mountain communities of the western Rif (Morocco): An ethnoarchaeological project. In: Ethnobotanist of distant pasts: Archaeological and ethnobotanical studies in honour of Gordon Hillman (Fairbairn, A., Weiss, E. Eds.), Oxbow, Oxford, p. 103-111.

Procopiou, H. \& Treuil, R., Eds, 2002, Moudre et Broyer. L'interprétation fonctionnelle de l'outillage de mouture et de broyage dans la Préhistoire et l'Antiquité, CTHS, Toulouse, vol. I, 238 p., vol. II, 238 p.

Raimond, C., Garine, E. \& Langlois, O., Eds), 2005, Ressources vivrières et choix alimentaires dans le bassin du lac Tchad, IRD-Prodig Éditions, Paris, 772 p.

Richards, A. I. 1939, Land, labour and diet in northern Rhodesia. Oxford University Press, London, 423 p.

Roux, V. 1985, Le Matériel de Broyage. Etude Ethnoarchéologique à Tichitt (R.I. Mauritanie), Éditions recherches sur les civilisations, Mémoire Vol. 58, A.D.P.F. Éditions, Paris, 112 p.

Samuel, D. 2010, Experimental Grinding and Ancient Egyptian Flour Production. In: Beyond the Horizon: Studies in Egyptian Art, Archaeology and History in Honour of Barry J. Kemp (Ikram, S. \& Dodson, A., Eds.), American University in Cairo Press, Cairo, p. 456-477.

Searcy, M. T. 2011, The Life-Giving Stone: Ethnoarchaeology of Maya Metates. The University of Arizona Press, Tucson, 168 p.

Selsing, L. E., Ed. 2014, Seen through a millstone. Geology and archaeology of quarries and mills, Museum of Archaeology, University of Stavanger, Bergen, 255 p.

Simango, C. 1997, Potential use of traditional fermented foods for weaning in Zimbabwe. Social Science and Medicine, 44: 1065-1068. doi:10.1016/s0277-9536(96)00261-4

Stephen, A.M. 1936, Hopi Journal (E.C. Parsons, Ed.) Columbia University Press, New York, 767 p.

Teklu, G. 2012, Ethnoarchaeological study of grind stones at Lakia'a in Adwa, Tigray regional State, Ethiopia, PhD Thesis, Addis Ababa University, Ethiopia, 103 p.

Tombul, M. 2005, Grain mills in ancient and modern northwestern Anatolia. In: Ethnoarchaeological Investigations in Rural Anatolia, vol. II (Takaoglu, T. Ed.), Ege Yayinlari, Istambul, p. 137-152. 
Valamoti, S. M. 2011, Ground cereal food preparations from Greece: the prehistory and modern survival of traditional Mediterranean 'fast foods'. Archaeological and Anthropological Sciences, 3(1): 19-39. doi:10.1007/s12520-011-0058-z

Valamoti, S. M., Jacomet, S., Stika, H.-P. \& Heiss, A. G. 2017, The PLANTCULT Project: identifying the plant food cultures of ancient Europe. Antiquity, 91(358). doi:10.15184/aqy.2017.130

Valamoti, S. M., Chondrou, D., Bekiaris, T., Ninou, Alonso, N., Bofill, M., Ivanova, M., Laparidou, S., McNamee, C., Palomo, A., Prats, G., Procopiou, H. \& Tsartsidou, G. 2020, Plant foods, stone tools and food preparation in prehistoric Europe: an integrative approach in the context of ERC funded project PLANTCULT. Journal of Lithic Studies, 7(3). doi:10.2218/jls.3095

Williams, D. \& Peacock, D., Eds. 2011, Bread for the People: The Archaeology of Mills and Milling. Proceedings of a Colloquium Held in the British School at Rome, $4^{\text {th }}-7^{\text {th }}$ November 2009, BAR International Series Vol. 2274, Archaeopress, Oxford, 359 p. 